University of Massachusetts Amherst

ScholarWorks@UMass Amherst

1990

\title{
A Comparison of Boosted-Discharge Hollow Cathode Lamps and an Inductively Coupled Plasma (ICP) as Excitation Sources in ICP Atomic Fluorescence Spectrometry
}

Stanley Greenfield

Loughborough University of Technology

Tariq M. Durrani

Loughborough University of Technology

Julian Tyson

University of Massachusetts Amherst

C. A. Watson

Follow this and additional works at: https://scholarworks.umass.edu/chem_faculty_pubs

Part of the Chemistry Commons

\section{Recommended Citation}

Greenfield, Stanley; Durrani, Tariq M.; Tyson, Julian; and Watson, C. A., "A Comparison of Boosted-Discharge Hollow Cathode Lamps and an Inductively Coupled Plasma (ICP) as Excitation Sources in ICP Atomic Fluorescence Spectrometry" (1990). Spectrochimica Acta Part B. 1379.

Retrieved from https://scholarworks.umass.edu/chem_faculty_pubs/1379 


\title{
A comparison of boosted-discharge hollow cathode lamps and an inductively coupled plasma (ICP) as excitation sources in ICP atomic fluorescence spectrometry
}

\author{
S. Greenfield, T. M. Durrani and J. F. Tyson \\ Department of Chemistry, University of Technology, Loughborough, Leicestershire, LE11 3TU, U.K. \\ and \\ C. A. Watson \\ Starna Ltd., 33 Station Road, Chadwell Heath, Essex, U.K.
}

(Received 1 June 1989; in revised form 31 August 1989)

\begin{abstract}
Copper, nickel and lead boosted-discharge hollow cathode lamps, run at recommended currents, have been compared with a high-powered inductively coupled plasma (ICP) as excitation sources in atomic fluorescence spectrometry (AFS). A similar comparison was made with a copper lamp run at higher currents. It was found that for lead and nickel, the fluorescence spectra differed in the relative intensities of the transitions observed with the two sources. No evidence was found for a difference in radiances between the two sources when the lamp was overrun. Although the lamps gave rise to lower blank standard deviation values, detection limits were worse because of poorer sensitivity due to the inability of the circular source to illuminate the required atom cell volume in the atomiser. It was concluded that the ICP was the better source, when the criterion is detection limits, but the lamps may be more convenient in some circumstances.
\end{abstract}

\section{INTRODUCTION}

THE UTILISATION in analytical work of the phenomenon of atomic fluorescence (AF) by means of the dual plasma (ASIA) instrument previously described [1-4], has been shown to have all but one of the attributes of inductively-coupled plasma atomic emission spectrometry (ICPAES) [5] and to be vastly superior with respect to spectral interference [6].

The one failing of the technique at the present time is the rather worse detection limits which are attainable for the refractory elements when compared with ICP-AES. As part of a continuing study of the technique, with a view to redressing this failing, experiments are being made to improve the efficiency of energy transfer between the source and the atomiser.

It seemed sensible before proceeding too far along this track to ascertain whether or not a high-powered plasma was a better source in atomic fluorescence than more conventional sources. In the experiments to be described the performance of such a plasma was compared with that of boosted-discharge hollow cathode lamps (BDHCL) [7] when used as sources in atomic fluorescence. A secondary objective was to study the performance of the BDHCL when run at higher primary currents than those normally used.

\section{EXPERIMENTAL}

\section{Instrumentation}

The ASIA instrument, shown schematically in Fig. 1, was as previously described [8] with the following substitutions:-

(1) a de Galan nebuliser [9-11] for the GMK nebuliser supplying aerosol to the source plasma; (2) a Gilson (8 channel Miniplus 2) variable speed peristaltic pump for the Ismatec pump used for sample transport to the atomiser plasma nebuliser; (3) a computer (Apple IIe) for the "Datacomp"; (4) all four lenses with $5.08 \mathrm{~cm}$ diameter, $5.08 \mathrm{~cm}$ focal length lenses.

The position of the lenses was such that on the excitation side, in the normal ASIA mode of operation or with the lamp in position 1, an image of magnification 1 was formed at the chopper and an image of magnification 0.2 was formed in the atomiser plasma. On the emission side, the lenses were placed so as to form images of magnification 1 at both the intermediate position and the 


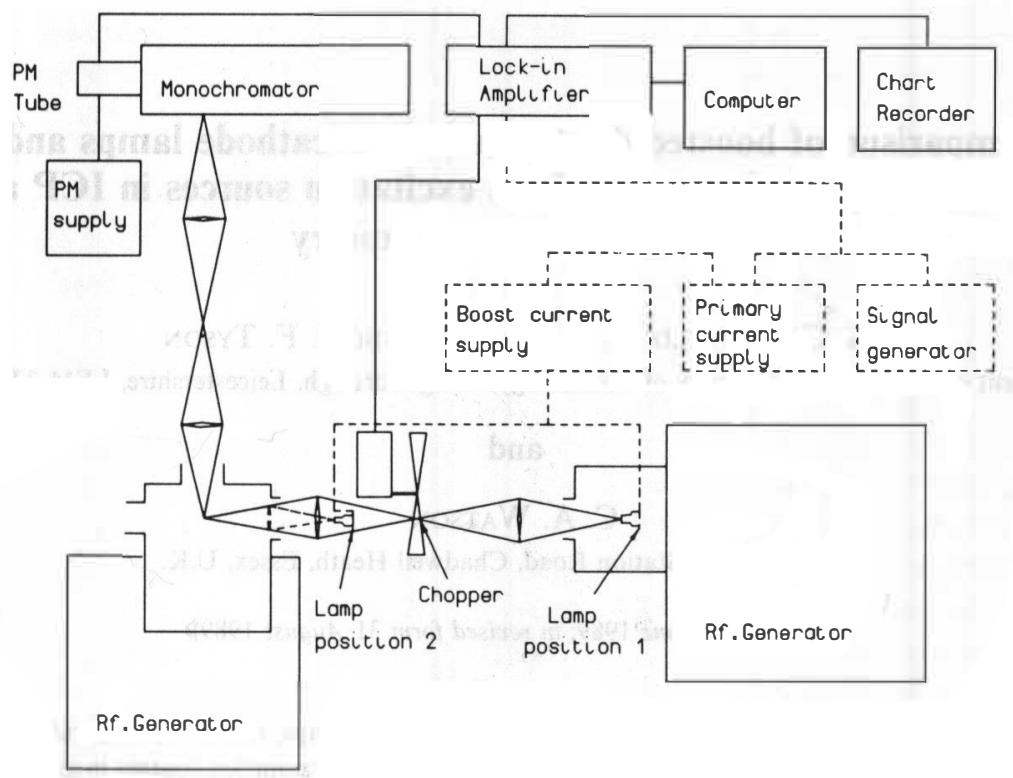

Fig. 1. Schematic diagram of experimental arrangement used for measurements.

monochromator entrance slit. With the hollow cathode lamp in position 2 (see Fig. 1) the lens was positioned so as to produce an image of magnification 1 in the atomiser plasma. The hollow cathode lamps had a source area of $7.07 \mathrm{~mm}^{2}$ (circle of diameter $3 \mathrm{~m}$ ).

A primary current power supply (Varian-Techtron, Australia, Type MLS 1A) was used to provide primary current to the lamps.

A boosted lamp power supply (Photron P8000, Photron (PTY) Ltd., Melbourne, Australia, available from Starna Ltd., Chadwell Heath, Essex, U.K.) was used to provide boost current to the lamps. The hollow cathode lamps used for the experiment were "Super Lamp" boosted-discharge lamps (Photron, Australia, supplied by Starna Ltd.). The lamp position and the optics were aligned with the aid of a $\mathrm{He} / \mathrm{Ne}$ laser.

A signal generator (Advance $\mathrm{H} 4$ audio-generator) was used to provide a square wave modulation of primary and boost currents to the lamps. The mechanical chopper on the ASIA instrument was not used with the lamps.

A neutral density filter was placed at the entrance slit of the monochromator for some experiments to prevent overloading of the photomultiplier tube (PMT) tube.

\section{Chemicals}

All chemicals used in this work were of analytical reagent grade. Dilutions were made in de-ionised water.

\section{Optimisation}

All optimisations were carried out using the method of Alternating Variable Search (AVS) previously described [21]. This method has been found to be preferable to Simplex methods when using the ASIA instrument.

\section{Lamp operating conditions}

Experimental variables (primary and boost currents) for the lamps were optimised for each experiment to give the maximum AF signal. The highest signal for each element was obtained, initially, by running the lamps at the maximum operating primary currents recommended by the manufacturer and adjusting the boost current to obtain maximum response. It was noticed that the signal decreased strongly when either the primary or the boost currents were decreased from the optimum, as shown for copper in Figs 2, 3. The initial operating conditions are shown in Table 1. The maximum slit width of the monochromator of $3.6 \mathrm{~mm}$ was used as this maximised the radiant flux and also permitted a contribution to the AF signal from other lines included in the $5.76 \mathrm{~nm}$ effective bandpass. The lead and copper lamps were tested for their intensity compared with an ordinary HCL, and it was noticed that about ten times higher signal was obtained with the BDHCL. 


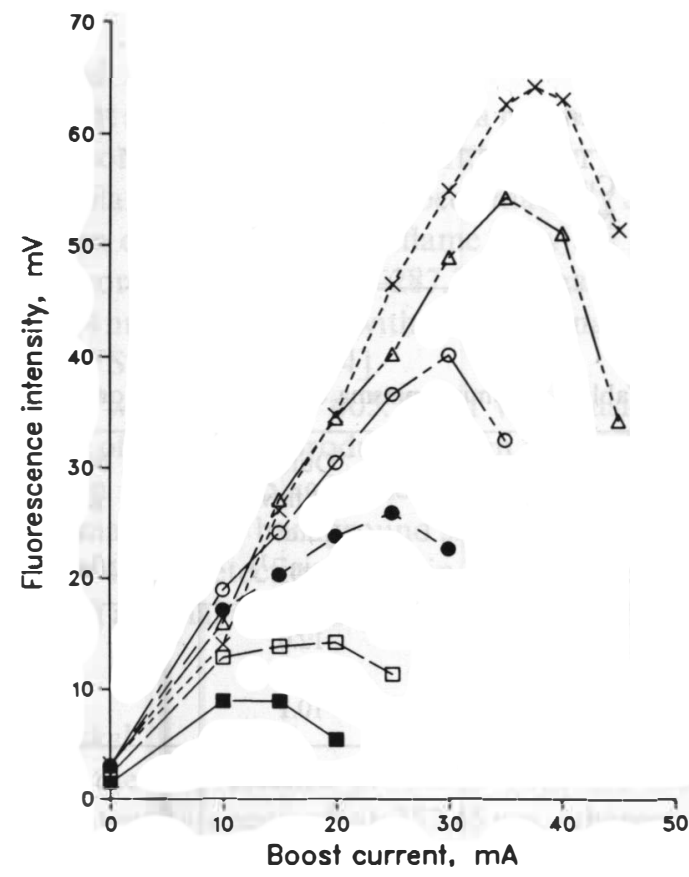

Fig. 2. Effect of boost current op atomic fluorescence signal of copper at different primary currents using lamp in position 2. (口) $6 \mathrm{~mA}$; $(\square) 8 \mathrm{~mA} ;(\bigcirc) 10 \mathrm{~mA} ;(\bigcirc) 12 \mathrm{~mA} ;(\Delta) 14 \mathrm{~mA} ;(\times) 15 \mathrm{~mA}$.

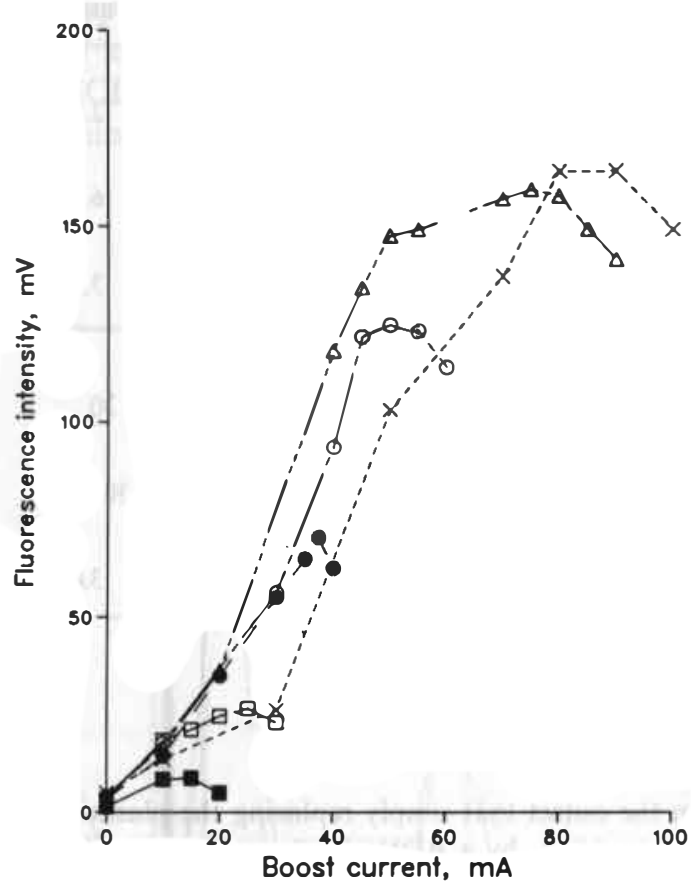

Fig. 3. Effect of boost current on atomic fluorescence signal of copper at different primary currents

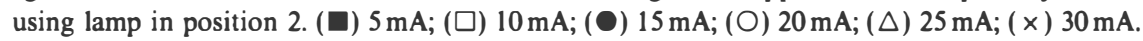

\section{Plasma operating conditions}

The optimised operating conditions for the atomiser plasma, used in conjunction with the BDHCL, are shown in Table 2, and the optimised operating conditions for the source and atomiser plasmas used in ASIA are shown in Table 3. Again, the maximum slit width of the monochromator was used. 
Table 1. Lamp operating conditions

\begin{tabular}{lcl}
\hline & \multicolumn{2}{c}{ Currents $(\mathrm{mA})$} \\
Elements & Primary & Boost \\
\hline $\mathrm{Cu}$ & 15 & 37.5 \\
$\mathrm{Ni}$ & 20 & 30 \\
$\mathrm{~Pb}$ & 10 & 25 \\
\hline
\end{tabular}

Table 2. Atomiser plasma operating conditions

\begin{tabular}{lccccc}
\hline Element & $\begin{array}{c}\text { Height } \\
\text { above the } \\
\text { coil }(\mathrm{cm})\end{array}$ & $\begin{array}{c}\text { Power } \\
(\mathrm{kW})\end{array}$ & $\begin{array}{c}\text { Outer } \\
\text { gas flow } \\
\text { rate* } \\
\left(1 \mathrm{~min}^{-1}\right)\end{array}$ & $\begin{array}{c}\text { Nebuliser } \\
\text { gas flow } \\
\text { rate* } \\
\left(1 \mathrm{~min}^{-1}\right)\end{array}$ & $\begin{array}{c}\text { Liquid } \\
\text { Uptake } \\
\text { rate } \\
\left(\mathrm{mlmin}^{-1}\right)\end{array}$ \\
\hline $\mathrm{Cu}$ & 10.5 & 0.453 & 12.0 & 2.6 & 2.0 \\
$\mathrm{Ni}$ & 10.3 & 0.517 & 12.0 & 2.6 & 2.5 \\
$\mathrm{~Pb}$ & 10.1 & 0.420 & 10.1 & 2.6 & 2.5 \\
\hline
\end{tabular}

* Argon gas was used.

Table 3. ASIA operating conditions

\begin{tabular}{|c|c|c|c|c|c|c|}
\hline \multirow[b]{2}{*}{ Parameters } & \multicolumn{2}{|c|}{ Copper } & \multicolumn{2}{|c|}{ Lead } & \multicolumn{2}{|c|}{ Nickel } \\
\hline & $\begin{array}{l}\text { Atomiser } \\
\text { plasma }\end{array}$ & $\begin{array}{l}\text { Source } \\
\text { plasma }\end{array}$ & $\begin{array}{l}\text { Atomiser } \\
\text { plasma }\end{array}$ & $\begin{array}{l}\text { Source } \\
\text { plasma }\end{array}$ & $\begin{array}{l}\text { Atomiser } \\
\text { plasma }\end{array}$ & $\begin{array}{l}\text { Source } \\
\text { plasma }\end{array}$ \\
\hline $\begin{array}{l}\text { Height above } \\
\text { the coil }(\mathrm{cm})\end{array}$ & 10.5 & 2 & 10.1 & 2.3 & 10.3 & 2.0 \\
\hline $\begin{array}{l}\text { Power in the } \\
\text { plasma }(\mathrm{kW})\end{array}$ & 0.45 & 7.3 & 0.42 & 6.5 & 0.52 & 7.3 \\
\hline $\begin{array}{l}\text { Nebulizer gas flow } \\
\text { rate* }\left(1 \min ^{-1}\right)\end{array}$ & 2.6 & 4 & 2.6 & 3.5 & 2.8 & 3 \\
\hline $\begin{array}{l}\text { Intermediate gas } \\
\text { flow rate* } \\
\left(1 \mathrm{~min}^{-1}\right)\end{array}$ & & 30 & & 30 & & 30 \\
\hline $\begin{array}{l}\text { Outer gas flow } \\
\text { rate }\left(1 \min ^{-1}\right)\end{array}$ & 12 & $30 \mathrm{Air}$ & 10.1 & $30 \mathrm{Air}$ & 12 & $30 \mathrm{Air}$ \\
\hline $\begin{array}{l}\text { Liquid uptake } \\
\left(\mathrm{ml} \mathrm{min}^{-1}\right)\end{array}$ & 2.0 & 3.0 & 2.5 & 3.0 & 2.5 & 3.0 \\
\hline
\end{tabular}

* Argon gas was used except where otherwise indicated.

Modus operandi

It was appreciated from the outset that simply replacing the plasma torch on the high powered generator, used as a source in ASIA, by a BDHCL (Position 1, Fig. 1) was unlikely to yield good detection limits (DL) for the elements, since the size of the image from the BDHCL would form a very small fluorescence cell in the atomiser plasma. Nevertheless, it was thought best to confirm this prediction.

Having confirmed this belief, the BDHCL was next placed in a position ( 2 in Fig. 1) where the beam from the lamp would just fill the diameter of the atomiser tailflame, and DLs were then determined. Even so, the size of the irradiated area in the atomiser tailflame was still much smaller than that irradiated when the high powered ICP was used as a source $(3 \mathrm{~mm}$ diameter circle compared with a $3 \times 10 \mathrm{~mm}$ rectangle, i.e. $7 \mathrm{~mm}^{2}$ vs $30 \mathrm{~mm}^{2}$ ). Therefore an experiment was conducted where a $3 \mathrm{~mm}$ aperture was placed close to the atomiser tailflame, thus reducing the area irradiated by the source plasma in an attempt to form an image area approximately the same as that produced by the lamp. 


\section{RESUlts AND Discussion}

\section{Atomic fluorescence of lead}

With the BDHCL as light source it was found that a much stronger signal was obtained at $405.78 \mathrm{~nm}$ (direct line fluorescence) compared with other lines such as $283.3 \mathrm{~nm}$ and $363.96 \mathrm{~nm}$ (see Fig. 4). Similar observations have been made by SYChra and Matousek [13]. However, when irradiation of the atomiser tailflame is by the source plasma in ASIA, the most sensitive region in fluorescence is $\Sigma 280.2-287.3 \mathrm{~nm}$ (again see Fig. 4). It is interesting to note that DeMERs used $364 \mathrm{~nm}$ for detection with conventional hollow cathode lamps in the commercial HCL-ICP-AFS instrument [14].

Having settled upon a wavelength of $405.78 \mathrm{~nm}$ when using the BDHCL as source, measurements were made of the signal produced when aspirating a $50 \mu \mathrm{g} / \mathrm{ml}$ lead solution with the lamp in position 1 and a $5 \mu \mathrm{g} / \mathrm{ml}$ lead solution with the lamp in position 2 . Measurements were also made of the background signals for each position of the lamp. The results are shown in Table 4 and detection limits in Table 5. Detection limits are calculated as the concentration giving a signal equal to three times the standard deviation of the blank response.

\section{Atomic fluorescence of nickel}

A wavelength scan of the fluorescence produced with the nickel BDHCL as source showed that maximum intensity occurred at $352.45 \mathrm{~nm}$, whereas in ASIA the maximum fluorescence occurred over $\Sigma 231.10-232.5 \mathrm{~nm}$ (Fig. 5). Solutions of 20 and $1 \mu \mathrm{g} / \mathrm{ml}$ were aspirated with the lamp in positions 1 and 2, respectively. Again, DL were determined at the appropriate wavelength following optimisation of all operating conditions, and these are shown in Tables 4 and 5.

\section{Atomic fluorescence of copper}

The resonance line of copper at $324.8 \mathrm{~nm}$ was found to be the most sensitive in fluorescence for the BDHCL as source and in ASIA, and the DL at the two lamp positions and in ASIA were determined and are shown in Table 5.

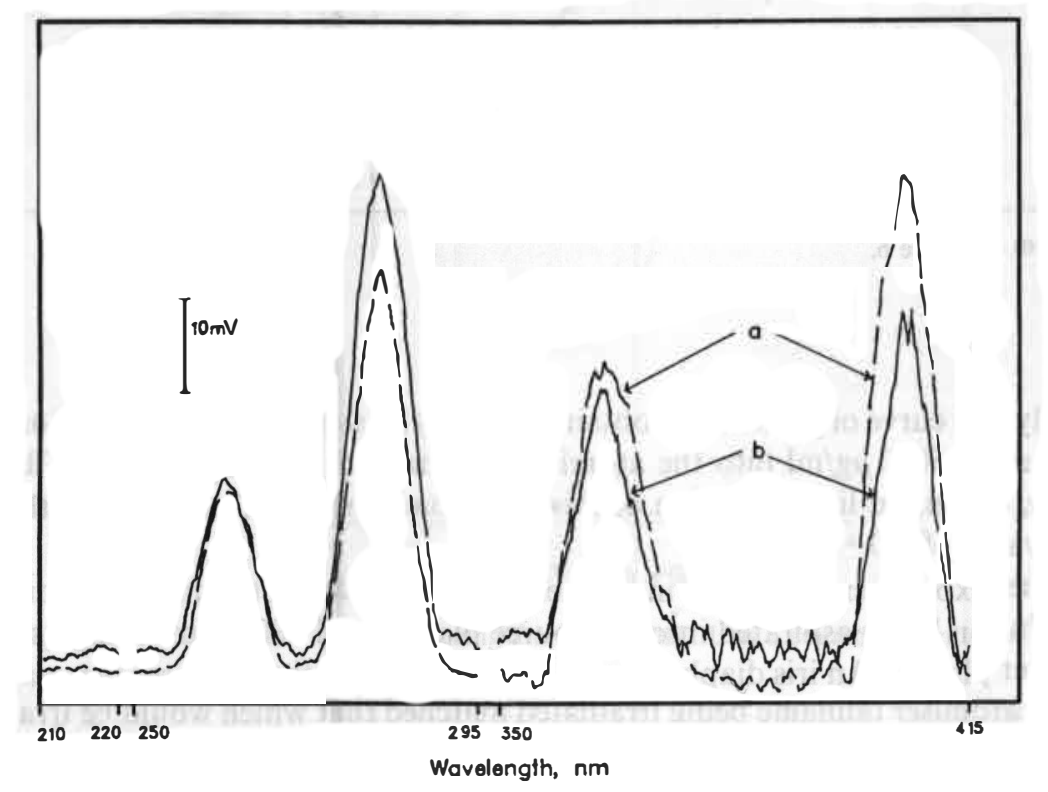

Fig. 4. (a) Atomic fluorescence for lead using the lamp as a source of excitation while aspirating $50 \mu \mathrm{g} / \mathrm{ml}$ lead solution into the atomiser plasma. (b) Atomic fluorescence spectrum for lead using the ICP as a source of excitation while aspirating $1 \mu \mathrm{g} / \mathrm{ml}$ and $20 \%$ lead solutions into the atomiser and source plasmas respectively. 
Table 4. Signals and noise results for various modes of operation

\begin{tabular}{lclcccc}
\hline Element & Concn $(\mu \mathrm{g} / \mathrm{ml})$ & Mode* & Mean signal $(\mathrm{mV})$ & SD $(\mathrm{mV})$ & Rel SD. (\%) & $n$ \\
\hline $\mathrm{Pb}$ & 0.00 & Lampl & 0.091 & 0.060 & 66 & 10 \\
$\mathrm{~Pb}$ & 50.0 & Lampl & 1.41 & 0.092 & 6.5 & 10 \\
$\mathrm{~Pb}$ & 0.00 & Lamp2 & 0.128 & 0.070 & 55 & 10 \\
$\mathrm{~Pb}$ & 5.00 & Lamp2 & 2.92 & 0.122 & 4.2 & 6 \\
$\mathrm{Ni}$ & 0.00 & Lampl & 0.094 & 0.050 & 53 & 10 \\
$\mathrm{Ni}$ & 20.0 & Lampl & 1.25 & 0.070 & 5.6 & 10 \\
$\mathrm{Ni}$ & 0.00 & Lamp2 & 0.197 & 0.070 & 36 & 10 \\
$\mathrm{Ni}$ & 1.00 & Lamp2 & 2.16 & 0.087 & 4.0 & 5 \\
$\mathrm{Cu}$ & 0.00 & Lampl & 1.84 & 0.097 & 5.3 & 10 \\
$\mathrm{Cu}$ & 3.00 & Lampl & 4.91 & 0.142 & 2.9 & 10 \\
$\mathrm{Cu}$ & 0.00 & Lamp2 & 6.54 & 0.186 & 2.8 & 10 \\
$\mathrm{Cu}$ & 0.100 & Lamp2 & 10.6 & 0.248 & 2.3 & 10 \\
$\mathrm{Cu}$ & 0.00 & Lamp2-OR & 6.62 & 0.220 & 3.3 & 10 \\
$\mathrm{Cu}$ & 0.050 & Lamp2-OR & 13.0 & 0.253 & 1.9 & 3 \\
$\mathrm{Cu}$ & 0.00 & ASIA & 10.4 & 0.260 & 2.5 & 10 \\
$\mathrm{Cu}$ & 0.020 & ASIA & 17.1 & 0.758 & 4.4 & 5 \\
$\mathrm{Cu}$ & 0.00 & ASIA-STP & 7.55 & 0.250 & 3.3 & 10 \\
$\mathrm{Cu}$ & 0.100 & ASIA-STP & 16.1 & 0.340 & 2.1 & 10 \\
\hline
\end{tabular}

* Lampl, BDHCL in position 1; Lamp2, BDHCL in position 2; Lamp2-OR, BDHCL in position 2 and over-run; ASIA, in ASIA; ASIA-STP, ASIA with image stop.

Table 5. Sensitivities, noise and detection limits

\begin{tabular}{lclccc}
\hline Element & Wavelength $(\mathrm{nm})$ & mode & sens $(\mathrm{mV}$ per ng/ml) & $\begin{array}{c}\text { SD of } \\
\text { blank }(\mathrm{mV})\end{array}$ & DL $(\mathrm{ng} / \mathrm{ml})$ \\
\hline $\mathrm{Pb}$ & 405.78 & Lampl & $2.64 \times 10^{-5}$ & 0.060 & 6800 \\
$\mathrm{~Pb}$ & 405.78 & Lamp2 & $5.58 \times 10^{-4}$ & 0.070 & 380 \\
$\mathrm{~Pb}$ & $\Sigma 280.2-287.3$ & ASIA & - & - & $80^{ \pm}$ \\
$\mathrm{Ni}$ & 352.45 & Lampl & $5.76 \times 10^{-5}$ & 0.050 & 2600 \\
$\mathrm{Ni}$ & 352.45 & Lamp2 & $1.96 \times 10^{-3}$ & 0.070 & 110 \\
$\mathrm{Ni}$ & $\Sigma 231.1-232.5$ & ASIA & - & - & $21^{ \pm}$ \\
$\mathrm{Cu}$ & 324.80 & Lampl & $1.02 \times 10^{-3}$ & 0.097 & 290 \\
$\mathrm{Cu}$ & 324.80 & Lamp2 & $4.10 \times 10^{-2}$ & 0.186 & 14 \\
$\mathrm{Cu}$ & 324.80 & Lamp2-OR & $1.27 \times 10^{-1}$ & 0.220 & 5.2 \\
$\mathrm{Cu}$ & $\Sigma 324.8-327.4$ & ASIA & $3.33 \times 10^{-1}$ & 0.260 & 2.3 \\
$\mathrm{Cu}$ & $\Sigma 324.8-327.4$ & ASIA-STP & $8.56 \times 10^{-2}$ & 0.250 & 8.8 \\
\hline
\end{tabular}

\pm Values from reference 6.

An analytical curve of growth was obtained (Fig. 6) by aspirating concentrations of copper solution, up to $5000 \mu \mathrm{g} / \mathrm{ml}$ into the atomiser plasma with the copper BDHCL as source. Unusually, the initial linear portion of this curve had a slope of about 1.3 rather than the expected value of 1.0 .

In another experiment the ASIA instrument was run under optimum conditions with $20 \%$ copper solution being aspirated into the source plasma and $100 \mathrm{ng} / \mathrm{ml}$ being aspirated into the atomiser plasma. An iris diaphragm was placed close to the atomiser plasma so that the area of the atomiser tailflame being irradiated matched that which would be irradiated by a copper BDHCL, and DL were determined. The results are shown in Tables 4 and 5.

The last experiment with the copper lamp was to operate it at higher primary currents, up to $30 \mathrm{~mA}$. The lamp was placed in position 2 and the metal casing covering the lamp was wrapped with a black damp cloth to avoid overheating the lamp envelope. The lamp primary current was varied in steps of $5 \mathrm{~mA}$ and the boost current optimised for maximum 


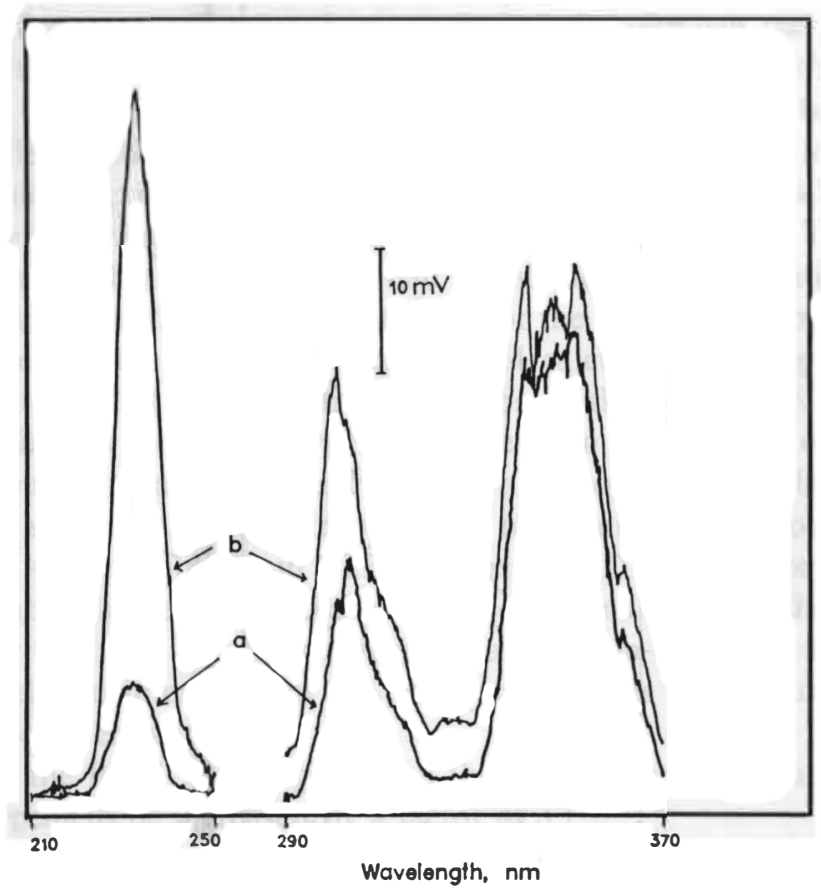

Fig. 5. (a) Scan of nickel fluorescence signal for BDHCL excitation. $50 \mu \mathrm{g} / \mathrm{ml} \mathrm{Ni}$ in atomiser. (b) Scan of nickel fluorescence signal for ICP excitation. $5 \mu \mathrm{g} / \mathrm{ml} \mathrm{Ni}$ in the atomiser, $20 \% \mathrm{Ni}$ in the source plasma.

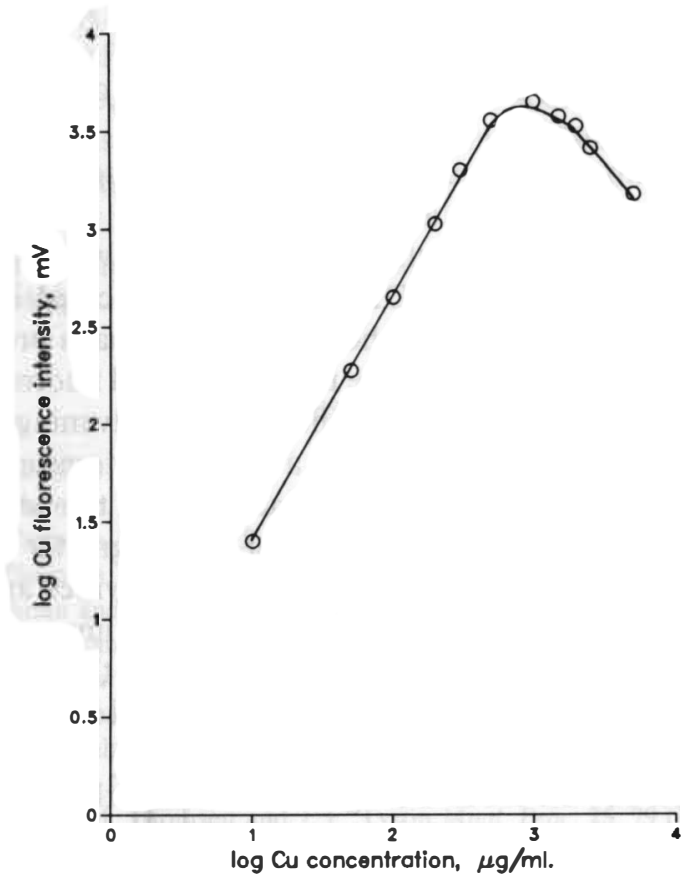

Fig. 6. Curve of growth for copper using a copper BDHCL as a source of excitation.

signal, while $1 \mu \mathrm{g} / \mathrm{ml}$ copper solution was aspirated into the plasma operated at optimised conditions.

The results (Fig. 5) showed that the copper AF signal increased as the primary current of the lamp increased. However, this increase was small above $25 \mathrm{~mA}$ primary current. Finally, a calibration curve was constructed (Fig. 7) at these new lamp operating conditions and a 


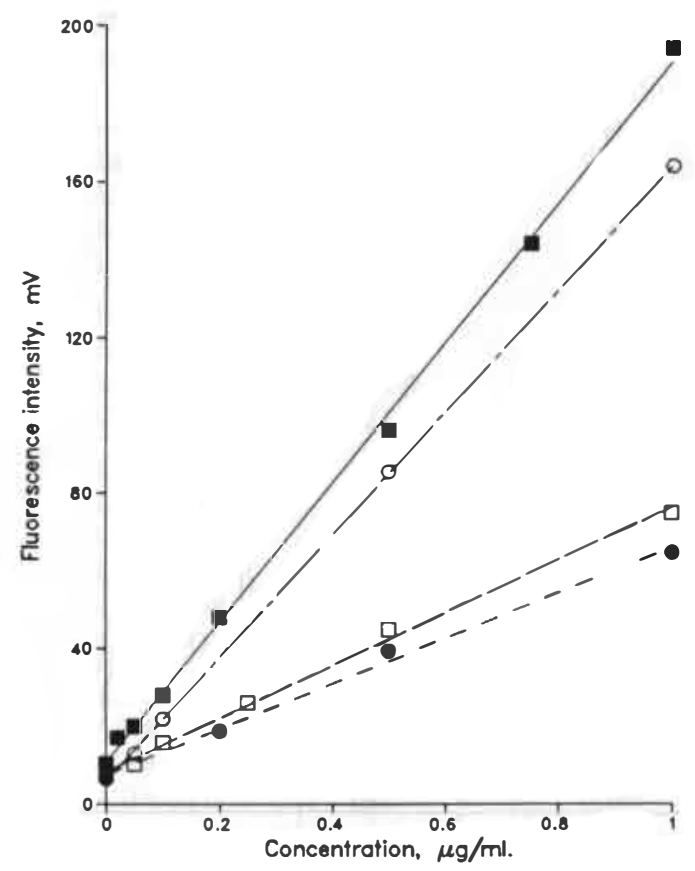

Fig. 7. Calibration graphs for copper using: (O) lamp operated at $15 \mathrm{~mA}$ and $37.5 \mathrm{~mA}$ primary and boost currents respectively; $(\square)$ ICP excitation with a $3 \mathrm{~mm}$ aperture while aspirating $20 \%$ copper solution into the source plasma; $(O)$ lamp operated at $30 \mathrm{~mA}$ and $85 \mathrm{~mA}$ primary and boost currents respectively; ( ) ICP excitation without any aperture and aspirating $20 \%$ copper solution into the source plasma.

$\mathrm{DL}$ of $5.2 \mathrm{ng} / \mathrm{ml}$ was obtained, as shown in Table 5 , based on the signal produced when aspirating a $50 \mathrm{ng} / \mathrm{ml}$ solution.

Figure 7 also shows calibration graphs for copper, using as sources the BDHCL operating at normal currents and the ICP with and without a stop.

As can be seen from Table 5, the detection limits are better with the ICP source than with the BDHCL sources even when the BDHCL source is located in a position in which maximum radiant power in the image in the atomiser plasma is produced (i.e. position 2 ). The results for copper suggest that this is due to the increased fluorescence signal sensitivity with the ICP source which more than offsets the BDHCL advantage of lower noise. As the monochromator can measure fluorescence from a cell in the atomiser tailflame irradiated by a $3 \mathrm{~mm} \times 10 \mathrm{~mm}$ image of the source plasma, it may be that the better performance of the plasma light source is due to its greater area rather than a greater intrinsic radiance. This possibility is suggested by the fact that very similar sensitivities and detection limits are obtained for the BDHCL and the plasma source when the image of the latter is stopped down to a circle of approximately $3 \mathrm{~mm}$ diameter. When the BDHCL is over-run, the sensitivity and detection limits are better than those obtained for the stopped down plasma source.

To determine whether the BDHCL has a greater radiance than the ICP, it was necessary to examine the effect of the different positions of the sources and the lens between the chopper position and the atomiser plasma. From the area of the lens (A) $\left(2027 \mathrm{~mm}^{2}\right)$ and the distance from intermediate image to the lens $\left(S_{1}\right)$ the solid angle gathered may be calculated $\left(A / S_{1}^{2}\right)$. The effect of moving a source from position 1 to position 2 in terms of the radiant power in the image, in the tailflame of the atomiser plasma, would be to increase this power by a factor of 9 . However, when the fluorescence sensitivities are compared for the BDHCL source in positions 1 and 2, the sensitivity advantage of position 2 varies from a factor of $21-40$, though the detection limit advantage remains constant at around 20 , for the three elements in this study. This suggests that additional factors contribute to the disadvantage of position 1 , such as absorption and reflection of light by the lenses and reduced absorption in 
the fluorescence cell due to the reduced image size produced when the source is in this position. This additional factor could be between 2.3 (for lead) and 4.4 (for copper).

The validity of the calculation of the image radiant power may be assessed by a calculation of the effect of the introduction of the stop to give a plasma source image of $3 \mathrm{~mm}$ diameter. This would be expected to reduce the intensity by a factor of 4.2 , and is in good agreement with the experimental ratios of fluorescence sensitivities (see Table 5) of 3.9.

It may be calculated that if the sources had equal radiances, the ratio of the copper fluorescence sensitivities for the ICP source to that for the BDHCL in position 2 would be 12. Taking into account the additional factor of 4.4 calculated for copper, it would be expected that the ratio would be 2.7 . As this is very close to the value of 2.6 measured, it may be concluded that there is no significant difference between the radiance of the ICP source and the BDHCL source run at the higher currents. It is recognised that this result does not imply that the two sources have similar excitation mechanisms. It is considered that the high-power plasma source would be in LTE whereas the BDHCL source would not. That there are considerable differences in excitation mechanisms between the two sources is shown in Fig. 4 for lead and Fig. 5 for nickel. It can be seen that there is a considerable difference in the relative intensities of the fluorescence lines and hence in the relative intensities of the source emission lines.

For operation of the BDHCL at higher than the recommended operating currents, the radiance would appear to be increased by a factor of 3.1 .

It is concluded, therefore, that a significant improvement in the performance of the instrument could be obtained by increasing the power in the image of the ICP source formed in the atomiser plasma tailflame. Work is proceeding in this laboratory to modulate the flow of aerosol to the source plasma which will enable the removal of the chopper and the use of a single lens to reduce the image so that it just fills the tailflame of the atomiser.

From the foregoing argument it is reasonable to conclude that a high-powered ICP is a better excitation source in AFS than BDHCL, if the figure of merit is DL. Nevertheless, BDHCLs are obviously useful sources and in some instances may prove to be more convenient than an ICP. Also, the lamps do allow of the possibility that existing owners of ICP-AES monochromator instruments may use the lamps to carry out AF experiments by easy, relatively cheap, retrofits.

Acknowledgement-Financial support for TMD from the Ministry of Science and Technology, Government of Pakistan is gratefully acknowledged.

\section{REFERENCES}

[1] S. Greenfield, Anal. Proc. 21, 61 (1984).

[2] S. Greenfield and M. Thomsen, Spectrochim. Acta 40B, 1369 (1985).

[3] S. Greenfield and M. Thomsen, European Spectrosc. News 68, 8 (1986).

[4] S. Greenfield and M. Thomsen, Anal. Proc. 24, 22 (1987).

[5] S. Greenfield, M. S. Salman and J. F. Tyson, Spectrochim. Acta 43B, 1087 (1988).

[6] S. Greenfield, K. F. M. Malcolm and M. Thomsen, J. Anal. Atom. Spectrom. 2, 711 (1987).

[7] R. M. Lowe, Spectrochim. Acta 26B, 201 (1971).

[8] S. Greenfield and M. Thomsen, Spectrochim. Acta 41B, 677 (1986).

[9] P. A. M. Ripson and L. de Galan, Spectrochim. Acta 36B, 71 (1981).

[10] P. S. C. van de Plas and L. de Galan, Spectrochim. Acta 39B, 1161 (1984).

[11] S. Greenfield, M. S. Salman, M. Thomsen and J. F. Tyson, Anal. Proc. 25, 79 (1988).

[12] S. Greenfield M. S. Salman, M. Thomsen and J. F. Tyson, J. Anal. Atom. Spectrom. 4, 55 (1989).

[13] V. Sychra and J. Matousek, Talanta, 17, 363 (1970).

[14] D. R. Demers, Spectrochim. Acta 40B, 93 (1985). 